\title{
Kant e as analogias musicais ${ }^{1}$
}

\section{(Kant and the musical analogies)}

\author{
Ubirajara RANCAN DE AZEVEDo MARQUES
}

Recibido: 28 de septiembre de 2011

Aceptado: 19 de diciembre de 2011

\section{Resumo}

Ademais do glossário filosófico, Kant emprega muitos outros repertórios linguísticos; dentre eles, por exemplo, o musical. O presente estudo, considerando o léxico musical kantiano, não tem como objetivo a promoção estética da música no cenário da filosofia crítica, mas o reconhecimento e a análise preliminar de um recurso argumentativo utilizado pelo filósofo, a saber, a analogia musical.

Palavras-chave: Kant, música analogia, harmonia, melodia.

\begin{abstract}
Besides a philosophical glossary, Kant handles many other linguistic repertoires; among them, for instance, the musical ones. The present study, by considering the kantian musical lexicon, is not intended to promote the music in the realm of critical philosophy from a aesthetic point of view, but to recognize and to examine

\footnotetext{
$1 \mathrm{O}$ texto a seguir compõe investigação em andamento apoiada pela Fundação de Amparo à Pesquisa do Estado de São Paulo ("Kant e a metáfora musical" (Processo no 2011/01002-1)). Todas as referências a escritos de Kant publicados na Akademie-Ausgabe são feitas de acordo com as siglas preparadas pela Kant-Forschungsstelle Mainz (disponíveis, por exemplo, em: $<$ http://www.sociedadekant.org/normas-para-citacoes/>. Acesso em: 18 mai. 2011). Quando não haja sigla cunhada para determinado escrito, será sempre citado por extenso o título original do mesmo. Salvo indicação em contrário, as traduções apresentadas são minhas.
} 
in a preliminary manner an argumentative resource used by the philosopher, namely, the musical analogy.

Keywords: Kant, music, analogy, harmony, melody.

[...] Die Music ist so zu sagen eine schöne sinnliche Erkenntniß.2

O presente estudo não tem por objetivo fornecer um catálogo das ocorrências de "música" e "musical" no corpus kantiano, nele não se encontrando, assim, o registro de cada uma das ocasiões nas quais esses termos (sobretudo o primeiro) comparecem nos escritos do filósofo. Por outro lado, as considerações vindouras tampouco objetivam uma espécie de ascensão estética da música, no cenário da filosofia crítica (em cuja "divisão das belas-artes", como se sabe, ela não ocupa lugar exatamente honroso), mas procuram reconhecer e explorar recurso algo frequente na obra do filósofo, a saber, as analogias musicais, ${ }^{3}$ destacando-se, para tanto, em especial, o par "harmonia" - "melodia", o que, então, permitirá aludir à conhecida polêmica entre Rameau e Rousseau.

Para além do glossário propriamente filosófico, Kant, com efeito, emprega outros tantos repertórios linguísticos, entre eles o musical: "melodia" e "harmonia", "notas", "sons" e "tons", "composição", "concerto", "consonância"4 e "dissonância" são alguns dos termos que também participam, assim, de seu arsenal discursivo.

Do ponto de vista filológico, embora ele também o faça (poucas vezes) mediante o latim "musica"5 e o francês "Musique"6, Kant dirige-se à arte dos sons musi-

\footnotetext{
2 Kant (2007), Refl, AA 15: 355. As probabilidades de datação dessa reflexão (“n. 806”) situam-na em arco demasiado largo, a saber, entre o início dos anos 1770 e o final dos anos 1780 .

3 No caso de Kant, parece-me sempre preferível o emprego de "analogia" ao de "metáfora", em conformidade com o que faz o próprio filósofo, que a utiliza copiosamente. Já "metáfora", bem pouco empregada por ele, encontra-se, por exemplo, nas "Preleções de Antropologia" (Dohna). Em passagem cujo tema é o "gênio", referindo-se ao fato de a palavra alemã "Genie" derivar não do francês "Génie", mas do latim "genius", Kant afirma: "Entre os antigos romanos, gênio era o espírito autêntico do homem, que começa no nascimento e cessa com a morte. Esse espírito estava associado ao homem para aconselhá-lo e desaconselhá-lo. Tal é uma forma metafórica e [uma] alegoria.” (Vorlesungen über Anthropologie (Kowalewski (1924) apud Kant (2007), p. 166)).

4 Kant emprega indistintamente "Consonanz" e "Consonantz". No Léxico de Zedler, encontra-se o vocábulo italiano "Consonanza", cuja definição assinala: "Consonanza, werden alle, dem Gehör angenehme intervalla, Mit- oder Einstimmungen genennet, sie mögen perfect, als die Octav und Quint, oder imperfect, als die Sext und Terz seyn. Man heisset sie auch Concordantias." (Zedler 1731)).

5 Cf. Kant (2007), OP, AA 21: 68.

6 Cf. id., V-MP/Mron, AA 29: 149; id., V-Lo/Blomberg, AA 24: 55; V-Lo/Blomberg, AA 24: 173; AA 24: 192.
} 
cais $^{7}$ (Kunst der Töne) sobretudo por meio de quatro palavras em alemão: "Tonkunst", germanização do latim "musica", e três termos parônimos entre si e provindos diretamente do mesmo vocábulo latino, e, em última instância, do grego "mousiké" ("Music"; "Musick"; "Musik")9. Se se tiver em mente o aspecto filológico-quantitativo, o maior número de referências nominais à música em Kant acha-se em primeiro lugar nas "Preleções", em seguida nas "Reflexões", especialmente, num caso e noutro, as dedicadas à antropologia. Não obstante isso, "música" se encontra em todas as repartições dos "Escritos Reunidos", quer se trate das "Obras" (a terceira Crítica e a Antropologia, em particular), da "Correspondência" (as cartas entre Hellwag e Kant, por exemplo10), do "Legado Manuscrito" (particularmente nas "Reflexões", como já notado, mas também no Opus postumum), quer, justamente, das "Preleções", dos anos 1760 aos anos 1790, inclusive, com predominância nos anos 70 e 90.

Mesmo que o assunto seja polêmico, merecendo debate próprio, não creio devase prescindir das "Reflexões" e "Preleções" de Kant sobre a matéria que for, particularmente quando se trate das analogias musicais (mas, igualmente, para citar dois outros casos, quando se tenha em vista a crítica do conhecimento e o debate embriológico, dos anos 1770 aos anos 1790). Se é fato que nem um nem outro conjunto de escritos estampa o mesmo nível de responsabilidade autoral existente nas "Obras", não é menos verdadeiro que ambos esses agrupamentos contêm preciosos registros conceituais de percurso - em perspectiva histórica e em perspectiva sistemática -, pelo que, em verdade, eles são, ao mesmo tempo, por assim dizer, a própria viagem e o diário que a registra e sobre ela reflete. Não será incorreto, portanto, ter esses aglomerados em conta, mas, sim, tê-los na conta de confirmação ou desmentido de quanto sustentem as "Obras", propriamente ditas. Com isso, ainda que os textos das "Preleções" possam em geral ser mais fluentes e inteiros do que os das "Reflexões", uns e outros não ultrapassam o limite das notas, com a diferença que, nas últimas, o material provém sempre diretamente de Kant (contendo, para alguns poucos exemplos, datação original precisa), ao passo que, nas primeiras, por mais que, para alguns casos, as "Preleções" se confirmem umas às outras (quando, então, diferentes procedências exibem textos entre si em tudo praticamente idênticos, gerando suficiente confiança quanto à fonte unívoca de todos eles), nas "Preleções", embora o material provenha substantivamente de Kant, ele, todavia, é formalmente de registro alheio.

\footnotetext{
${ }^{7} \mathrm{Na}$ terminologia musical em português, o alemão "Ton" será "som" ou "som musical", ao passo que o português "tom" será em alemão "Tonleiter" ("escala"). Por exemplo: "C-Dur Tonleiter" é em português o tom ou a escala de dó maior, e vice-versa.

8 Cf. Kant (2007), Refl, AA 15: 415.

9 Para o adjetivo "musical", Kant se vale dos parônimos "musicalisch" / "musikalisch".

10 A de Hellwag a Kant é de 13 de dezembro de 1790, ao passo que a de Kant a ele é de 3 de janeiro de 1791 .
} 
As referências denotativas ou não analógico-exemplificativas de Kant à "música" dão-se em contexto físico-matemático, téorico-musical e estético-musical. Já suas referências analógico-exemplificativas a ela dão-se em contexto fundamentalmente especulativo.

Do ponto de vista físico-matemático ${ }^{11}$, a música é considerada, por exemplo, nas "Preleções de Física" (Friedländer e Mrongovius) ministradas respectivamente em 1776 e 1785. Nas últimas, a "Sétima Seção" do texto intitula-se, precisamente: "Do som físico (Schall ${ }^{12}$ ) e dos sons musicais (Töne)". Newton e Euler são expressamente nomeados em ambas, podendo-se supor que assim tenha igualmente ocorrido em todas, as "Preleções de Física", tendo-se prolongado de 1755 a 1788, mas não ininterruptamente.

Em registro híbrido, teórico-musical e estético-musical, a música é abordada em diferentes escritos, como, por exemplo, na seguinte "reflexão": "Na música, por vezes tem de haver uma dissonância (Dissonanz); com isso, os tons agradáveis seguintes aprazem-nos ainda mais"13. Kant, aqui, alude à chamada "antecipação", termo que, empregado por ele e utilizado musicalmente à época ${ }^{14}$, parece não ocorrer com tal significado nos "Escritos Reunidos". Trata-se de adiantar, para o acorde em que se está, uma ou mais notas do acorde seguinte, as quais, harmonicamente estranhas ao acorde que as recebe, provocam desafinação. Esse efeito momentaneamente dissonante corresponderia, na música, ao que, em termos gustativos, é o chamado "dolce piccante", expressão inserida pelo filósofo em "reflexão" presumivelmente anterior a essa passagem das "Preleções de Antropologia" (Dohna), justamente ao lado de "dissonância"15.

11 Cf. Kant (2007), Refl, AA 14: 394; id., V-Lo/Philippi, AA 24: 353.

12 Conforme o Deutsches Wörterbuch von Jacob und Wilhelm Grimm (Grimm (1854)), "Schall" corresponderá aos vocábulos latinos "sonus, strepitus, rumor". Embora assim, não me parece aconselhável traduzi-lo simplesmente por "som" (cf., aqui, n. 7), tampouco vertê-lo por "estrépito" ou "rumor". 13 Kowalewski (1924) apud Kant (2007), p. 179 [Ko179].

14 "Anticipation". Também, para a mesma operação musical, os termos "Aufhaltung", "Retardation", "Verzögerung", "Vorausnahme", nenhum dos quais parece ter sido empregado musicalmente por Kant. Cf. Kant (2007), V-Lo/Philippi, AA 24: 357-358: "A música não fornece absolutamente nenhuns objetos ou descrições dos mesmos. A proporção (Proportion), que em nenhuma espécie de beleza (in keiner Art der Schönheit) é tão exata e tão múltipla como na música, é o que constitui a beleza da mesma."

15 Cf. id., Refl, AA 15: 264: "Schmertz schärft den Geschmak am Vergnügen (g dissonantz. dolce picqvante). Abentheuer zum Glüklichen Ausgange." Na nomenclatura adotada por Adickes, como se sabe, " $g$ " (indicativo de "gleichzeitiger Zusatz") remete a um aditivo contemporâneo da época de redação da "reflexão" de que se trate (ou, no dizer do próprio: "[...] gleichzeitiger Zusatz, derselben Schriftphase angehörig wie die Reflexion selbst") (Adickes (1911) apud Kant (2007), AA 14: LVII). Sobre o efeito harmônico a que Kant alude, nessa "reflexão", por outro lado, assim se pronunciava Sulzer na Teoria Geral das Belas-Artes: "Auch in der Musik gibt es größere und kleinere Aufhaltungen. In den größeren wird ein Gedanke so behandelt, dass er gerade an der Stelle, wo man glaubt, er werde durch den Schluss sein Ende erreichen, aufs neue eine andere Wendung 
Ainda no mesmo plano téorico-estético musical, essas "Preleções" apresentam a seguinte consideração de Kant: "Para uma boa música exigir-se-ão [...] duas coisas, a saber: o compasso (Takt) ou uma igual divisão do tempo, e, quando muitos sons musicais são reunidos, uma consonância (Consonanz) ou proporção (Proportion) dos mesmos"16. Já em "reflexão" presumivelmente anterior a essas "Preleções", manuscrita entre o final dos anos 1760 e o início dos anos 1770, Kant distinguia entre "consonância" e "harmonia":

O contraste (Abstechung) das cores é para o olho exatamente o que a consonância (Consonantz) é para o ouvido (Ohr). Se as cores estão misturadas (gemengt), tal é então a consonância propriamente dita (die eigentliche Consonantz); se elas estão uma ao lado da outra (neben einander), tal é então a harmonia (Harmonie). ${ }^{17}$

A relação existente nessa passagem, valendo-se do elemento comparativo musical ("consonância"; "harmonia"), é feita, por assim dizer, em favor das cores, não dos sons musicais. Daí que, do ponto de vista estritamente teórico-musical, sua conclusão apresente um certo paradoxo. Pois, em verdade, compreendendo-se que a mistura das cores corresponda à sonância conjunta, à "consonância", assim como que o arranjo das mesmas, uma ao lado da outra, resulte em "harmonia" - a partir do confronto desordem (mistura / consonância) versus ordem (lateralização / harmonia) -, já não se aceitará tão bem a consequência arquitetônico-musical de "harmonia" como disposição lateral de sons, o que, em verdade, identificará a "melodia", não a "harmonia". Apesar de se poder compreender a lateralidade cromática como simultânea, ao passo que a melódica como sucessiva, mesmo assim não se aceitará a lateralidade (simultânea ou sucessiva) da harmonia musical. Seja como for, a passagem em causa não opõe musicalmente "consonante" a "dissonante" (oposição presente à época), mas, se se quiser, o claro (a "harmonia") ao confuso (a "consonância" como sonância meramente conjunta, porém não disposta ordenadamente).

Com relação ao emprego analógico-exemplificativo de música, em Kant, será porventura útil, antes de abordá-lo, lembrar algo do conceito de "analogia" como "proporção". A esse respeito, há um bem conhecido passo do $\S 58$ dos Prolegômenos, no qual ela é conceituada, e pelo qual, a saber, tem-se que o conhecimento analógico, ao contrário do que comumente se pensa, não é "[...] uma seme-

bekommt. ${ }^{2}$ Kleinere Aufhaltungen kommen beständig bei Auflösung der Dissonanzen vor, da ein dissonierender Akkord, dessen Auflösung man erwartet, erst noch durch andere Dissonanzen geführt und danach aufgelöst wird." (Sulzer (1771)). A nota interna ("2") ao texto de Sulzer remete ao verbete "cadência (Kadenz)".

16 Kowalewski (1924) apud Kant (2007), p. 213 [Ko213].

17 Kant (2007), Refl, AA 15: 276. Embora "Disharmonie" e "disharmoniren" compusessem, à época, o léxico musical, Kant, que utiliza tais vocábulos, não parece fazê-lo em perspectiva musical. 
lhança imperfeita de duas coisas, mas uma semelhança perfeita de duas relações (Verhältnisse) entre coisas completamente dessemelhantes"18. Essa mesma significação de "analogia" apresenta-se também em algumas "Preleções" e "Reflexões", anteriores ou posteriores ao texto de 1783; por exemplo, em passagem das "Preleções de Metafísica” (Pölitz), do início da década de 90: “[...] Analogia significa tanto quanto a palavra proportio em matemática, a saber, uma comparação de duas relações (Verhältniße). Analogia é uma semelhança perfeita das relações das coisas, ainda que as próprias coisas sejam completamente dessemelhantes [...]"19. Ou, em passagem das "Preleções de Metafísica" (Dohna), de 1792-1793: “[...] Analogia - proporção - comparação de duas relações (Verhältniße); 1 está para 2, assim como 6 está para 12 [...]"20. Em contrapartida, num passo das "Preleções de Antropologia" (Pillau), de 1777-1778, encontra-se uma acepção de "analogia" a tomá-la preferivelmente como metáfora: "Há um uso analógico da razão quando se representa por imagens o que a razão devia conhecer a partir de conceitos" 21 .

Já na Crítica da Razão Pura, na parte consagrada às "Analogias da experiência", lê-se:

$\mathrm{Na}$ filosofia, analogias significam algo muito diverso daquilo que representam na matemática. Nesta, elas são fórmulas que enunciam a igualdade de duas relações de quantidades (Größenverhältnisse) e são sempre constitutivas, de forma que, quando dados três termos da proporção (Proportion), o quarto também é dado por eles, isto é, pode ser construído. Mas, na filosofia, a analogia não é a igualdade de duas relações quantitativas, mas qualitativas, em que, a partir de três termos dados, posso conhecer e dar a priori só a proporção (Verhältniß) a um quarto, não porém esse próprio quarto termo $[\ldots]^{22}$

Com isso, tem-se que: se " 1 " está para "2", como "x" para "12", "x" será ostensivamente construído a partir da proporção verificada nos termos dessa relação. $\mathrm{O}$ mesmo não se dá, contudo, se, por exemplo, é dito: "tonalidade” está para "música clássica", como "x" para "dodecafonismo". Nesse caso, "x" nunca será obtido por meio de uma "Exhibitio a priori" 23 , mas discursivamente, por encadeamento lógico, de modo que os termos da relação nos dão a proporção, não, porém, o conhecimento intuitivo do objeto correspondente à incógnita.

Todavia, a despeito da distinção entre uso matemático-constitutivo e filosóficoregulativo de analogia, essa passagem da primeira Crítica revela claramente a uni-

18 Id., Prol, AA 04: 357.27-29.

19 Id., V-MP-L2/Pölitz, AA 28: 605.

20 Id., V-MP/Dohna, AA 28: 695-696. Essa mesma definição aparece igualmente nos anos 1760 e 1770, no bojo de comentários de Kant à Metaphysica de Baumgarten, compondo ainda com notas do filósofo ao Auszug aus der Vernunftlehre de Meier (cf. Meier (1752) apud Kant (2007), AA 16: 3-872).

21 Kant (2007), V-Anth/Pillau, AA 25: 778.

22 Kant (2007), KrV, A 179-180; B 222.

23 Id., Refl, AA 16. 539. 
vocidade do sentido geral do conceito em ambos os domínios - tal se dando pela "proporção" -, só assim, de resto, impondo-se a diferença realçada, atinente ao "uso", não a uma ambivalência do mesmo conceito24.

Quanto ao emprego analógico-exemplificativo da música, em Kant, menciono agora somente dois casos, respectivamente atinentes à "influência recíproca das substâncias no mundo (der wechselseitige Einfluß der Substanzen in der Welt)"25 e ao conceito de causalidade, mais à frente sendo recordado outro, acerca do conceito de "representação".

Nas "Preleções de Metafísica" (Mrongovius), ministradas em 1782-1783, lê-se, com efeito:

O nexus idealis não é conexão nas próprias coisas, mas simplesmente na ideia do observador que as considera. Por exemplo: se ouço a mais agradável música, sinto em meu ouvido uma harmonia de todos os instrumentos. Essa harmonia, porém, está simplesmente em mim e em meus pensamentos; mas os instrumentos não têm a mínima harmonia um com o outro. 26

Já nas "Preleções de Metafísica" (Dohna), por sua vez:

É [...] completamente falso que o efeito tenha de ser homogêneo com a causa, pois precisamente nisso reside o conceito da causalidade, [a saber,] que por meio de algo, algo de realiter distinto é posto. Por exemplo: [o] toque de uma corda e o som musical (Berührung einer Saite und Ton).27

Passo agora às referências nas quais se observam as considerações de Kant sobre "melodia" e "harmonia".

Conforme recorda Piero Giordanetti, em seu Kant e la musica, o filósofo, segundo Adickes, "[...] poderia, graças a fontes indiretas, ter tido conhecimento da disputa entre Rameau e Rousseau." 28 A reflexão n. 639, por sinal (que, segundo Adickes, terá sido redigida entre 1768 e 1770), lembrada por Giordanetti, faz referência explícita a Rameau (será mesmo, parece, a única menção nominal do filósofo ao músico borgonhês):

24 Também na Crítica da Faculdade do Juízo, em nota de seu $§ 90$ (Kant (2007), KU, 05: 466), Kant falará da analogia "em sentido qualitativo (in qualitativer Bedeutung)", sem, com isso, desdizer a proporcionalidade intrínseca ao mesmo conceito.

25 Id., V-MP/Mron, AA 29: 865.

26 Ibid., p. 866.

27 Id., V-MP/Dohna, AA 28: 685.

28 Giordanetti (2001), p. 73. 
A forma sensível (ou a forma da sensibilidade) de um conhecimento apraz ou como um jogo da sensação (ein Spiel der Empfindung) ou como uma forma da intuição (imediatamente) ou como um meio para o conceito do bem. O primeiro [modo] é o estímulo; o segundo, o belo sensível; o terceiro, a beleza autônoma. O estímulo formal é ou imediato - rameau (sic) crê que ele esteja na música - ou mediato, como no riso e no choro [... $]^{29}$

Nessa "reflexão", presumivelmente fronteiriça entre o final dos anos 1760 e o início da década seguinte, sem mencionar a "harmonia" musical ou posicionar-se face a ela, Kant já alude ao "estímulo formal" e a Rameau, e, assim, supostamente à "harmonia".

Como quer que seja, um possível contato indireto de Kant com a teoria de Rameau poderá ter ocorrido por meio dos Éléments de musique théorique et pratique, suivant les principes de M. Rameau, texto de D'Alembert publicado em 1752 e traduzido para o alemão cinco anos depois por Friedrich Wilhelm Marpurg30. Segundo Howard Serwer, essa tradução "[...] foi largamente responsável pela propagação das teorias de Rameau na Alemanha"31.

No tocante a "harmonia" e a "melodia", conceitos que não por acaso Kant amiúde considera, há, à época, com relação a eles, um claro e documentado debate, do qual uma exemplar representação serão os escritos entre si polêmicos de Rousseau e Rameau.

Jean Ferrari, em seu ensaio "A querela Rousseau-Rameau", recorda que "[n]atureza, natural, leis da natureza, imitação da natureza", expressões comuns a ambos os autores, têm significados "totalmente diferentes" num e noutro. Assim, para Rameau,

[f]azer a teoria da música é inventar um procedimento científico que permita explicar a natureza do som de uma maneira inteligível e, numa tradição que remonta bem além de Descartes, matemática, partindo da experiência fundamental das cordas vibrantes. [...]

De acordo com Rousseau, em contrapartida, a música, prossegue Ferrari,

[...] é de uma outra essência, porque a natureza que ele invoca não é a das coisas, mas do homem. [...] [Uma música] será natural se ela falar ao coração, se for capaz de evocar todos os sentimentos, todas as emoções, todas as paixões da alma humana. [... $]^{32}$

Conhecida desde então na França como "querelle des Bouffons"33, a contenda estendeu-se por aproximadamente dois anos, entre 1752 e 1754, ainda que seus ecos

29 Kant (2007), Refl, AA 15: 276-277.

30 Cf. Marpurg (1757) apud Giordanetti (2001), p. 235.

31 Serwer (2011). Sobre a tradução de Marpurg, cf. Hirschmann (1999), p. 188 e seguintes.

32 Ferrari (1985), pp. 80-81.

33 Por alusão a La serva padrona, "opera buffa" de Pergolesi cuja encenação desencadeou o conflito. 
se tenham prolongado, do que dão testemunho, por exemplo, os verbetes "harmonia" e "melodia" no Dictionnaire de musique de Rousseau, publicado em 1775.

Conforme Rameau (cujo Traité de l'harmonie réduite à ses principes naturels fora publicado em 1722), a harmonia é "[...] a única base da música e o princípio de seus maiores efeitos [...]". Da mesma forma, “[...] é somente à Harmonia que compete agitar as paixões; a Melodia extrai sua força somente dessa fonte, da qual ela emana diretamente $[\ldots]$ "..34.

Tendo em mente a musica pratica, não a musica theoretica ${ }^{35}$, a estética musical, não a ciência da música, Rousseau, no Essai sur l'origine des langues (esboçado em 1755 mas publicado postumamente só em 1781, e cujo subtítulo anota: "où il est parlé de la Mélodie, et de l'Imitation musicale"), contra Rameau, Rousseau afirma:

Da mesma forma que [...] a pintura não é a arte de combinar as cores de uma maneira agradável à vista, tampouco a música é a arte de combinar os sons de uma maneira agradável ao ouvido. Se nada mais houvesse, uma e outra comporiam entre as ciências naturais, não entre as belas-artes. É somente a imitação que as eleva a esse grau. Ora, o que faz da pintura uma arte da imitação? O desenho. O que faz da música uma outra arte da imitação? A melodia. 36

Ora, considerando esteticamente "harmonia" e "melodia", nas "Preleções de Lógica" (Philippi), Kant, por volta de 1772, enfatiza:

Na música, a harmonia é a própria beleza e [é tal] para o entendimento; a melodia, porém, o estímulo ou a sensação. Aquela é universalmente válida e inalterável; esse, o estímulo, é diverso segundo a diversidade dos sujeitos. A melodia nada mais é senão sensações expressas por meio de sons. Conforme um sujeito seja mais ou menos inclinado para tais sensações, que o melódico de uma música expressa, [a música] é mais ou menos estimulante para [ele]. Fascinado (geblendet) pelo estímulo, alguns podem ter uma música medíocre e mesmo má por muito bela; só que assim não pensam outros. $[\ldots]^{37}$

Esse julgamento, mesmo que efetivamente proferido em 1772, concentra de uma vez por todas o parecer de Kant sobre "harmonia" e "melodia", quer quando elas sejam tomadas em sentido próprio, quer quando em sentido analógico.

A mesma contenda é também nomeada "guerre des coins", em referência aos que, como Rousseau, defendiam a música italiana e eram ditos do "coin de la reine", e aos que, como Rameau, defendiam a música francesa e eram ditos do "coin du roi".

34 Rameau (1754).

35 Acerca do background histórico de ambas essas expressões, cf., por exemplo: Bartel (1997), pp. 11-19.

36 Rousseau (1824), pp. 474-475. Kant, como Rousseau e tantos mais, compara com frequência "cores" e "sons".

37 Kant (2007), V-Lo/Philippi, AA 24: 352. 
Referência oficial para os cursos de Lógica, Kant seguia o Auszug aus der Vernunftlehre de Meier, em cujo $§ 22$, o qual o filósofo terá tido em mente na passagem ainda há pouco citada de suas "Preleções de Lógica", lê-se:

Quando o múltiplo num conhecimento conforma-se a uma intenção ou contém a razão suficiente da mesma, nisso então consiste a perfeição do conhecimento (perfectio cognitionis). As perfeições do conhecimento têm nele lugar ou à medida que ele é claro ou à medida que ele é obscuro [...]. Aquelas são as perfeições lógicas do conhecimento (perfectio cognitionis logica) e estas são nomeadas as belezas do mesmo (pulcritudo et perfectio aesthetica cognitionis). Por exemplo: a certeza matemática é uma perfeição lógica e a vivacidade pictórica uma beleza do conhecimento. ${ }^{38}$

Observe-se, pois, que Meier não só não menciona "harmonia" ou "melodia", como sequer a música, limitando-se a considerar a "beleza e a perfeição estética do conhecimento". Por conseguinte, Kant é quem insere, por conta própria, a explícita referência àquelas, reverberando localmente, talvez, o debate já então havido além-Reno. Considerando, agora explicitamente, esse mesmo $\S 22$ do Compêndio de Meier num conjunto de quatro "reflexões" (compreendido entre a n. 1752 e a n. 1755, todas redigidas presumivelmente entre 1752 e 1756 (e, então, aproximadamente à época da "querelle" entre Rameau e Rousseau)), o filósofo não se vale aí da mesma alusão, embora, em atenção ao texto considerado, pronuncie-se sobre "[...] a perfeição estética do conhecimento"39.

Também na reflexão n. 1676 (presumivelmente redigida por volta de 1752), agora em comentário aos $\S \S 10$ e 11 do Auszug de Meier ${ }^{40}$, Kant já se valia da música, de modo a, por meio dela, "explicar melhor" 41 , no dizer de Giordanetti, o conceito aí em foco, qual seja, o de "representação":

[...] O que [...], na representação, é [...] concordante com a coisa representada? A representação, posto que ela toma seu fundamento da coisa representada, convém nisso com a mesma, porque, desse modo, ela é composta a partir dos conceitos-parciais [da mesma], como a coisa inteira representada a partir de suas partes. Pode-se, por exemplo, dizer: as notas de uma peça musical são uma representação da ligação harmônica dos sons, não como se uma nota fosse semelhante a um som, mas sim porque, em tal ligação, as notas, umas sob as outras, são como os próprios sons. [...] $]^{42}$

Vê-se, nesse trecho, um claro exemplo do significado de analogia como proporção, tal qual exposto e empregado por Kant. Não se trata de afirmar que "nota" e

\footnotetext{
38 Meier (1752) apud Kant (2007), AA 16: 101-102.

39 Kant (2007), Refl, AA 16: 102.

40 Cf. Meier (1752) apud Kant (2007), AA 16: 4.

41 Giordanetti (2001), p. 52.

42 Kant (2007), Refl, AA 16: 78.
} 
"som" se assemelhem, mas que as relações entre as notas e as relações entre os sons são diretamente proporcionais. Quando leio um acorde na partitura - a tríade lá-dómi, por exemplo -, a relação entre suas partes componentes representa a relação entre as partes que constituem determinados três sons efetivos simultaneamente entoados.

Também num fragmento da reflexão n. 5750, redigida aproximadamente entre 1785 e 1788, Kant salienta: “[...] No ânimo, toda a ordenação está no tempo, e, na verdade, em sucessão. Reciprocamente, o que pode ser intuído sucessivamente é simultâneo. Harmonia e melodia. [...]"43 Nessa passagem, o filósofo tem presente o $\S 78$ da Metaphysica de Baumgarten, o primeiro da "Seção V", consagrada ao conceito de "ordem", o qual, nomeando a música, nem por isso tece uma analogia musical:

Se muitas coisas são postas junto umas das outras ou a seguir umas às outras, diz-se que ESTÃo LIGADAS. A ligação de muitas coisas pode ser ou da mesma [espécie] ou de diversa [espécie]. Se for a primeira, chama-se COORDENAÇÃO, e a sua identidade chamase ORDEM. Outrora a ciência da ordem era a MÚSICA ENTENDIDA NO SENTIDO MAIS AMPLO. 44

Sobre essa mesma passagem de Baumgarten, especificamente sobre a expressão "MÚSICA ENTENDIDA NO SENTIDO MAIS AMPLO", a reflexão n. 3545 (cuja datação é demasiado incerta), afirma: "Nonsense em que há método"45. Se, como parece, por referência à música (tendo sempre presente a atenção do texto original ao conceito de "ordem"), a reflexão de Kant apontará o contrasenso de a música, limitada às sensações, constituir-se ao mesmo tempo em exemplo de "ordem". Em assim sendo, contudo, o nonsense destacado pelo filósofo já estará como que musicalmente resolvido na reciprocidade entre harmonia e melodia, que ele mesmo aponta na reflexão n. 5750, há pouco lembrada. Ou seja: "[...] No ânimo, toda a ordenação está no tempo, e, na verdade, em sucessão. Reciprocamente, o que pode ser intuído sucessivamente é simultâneo. Harmonia e melodia. [...]"46

Relativamente ao texto original da obra de Baumgarten, Kant desdobra ou especifica a referência do autor à música (tal como no comentário à passagem, há pouco recordada, do Auszug de Meier), assim interpretando, à luz da mesma, respectivamente como "harmonia" e "melodia", o fragmento inicial do parágrafo em questão: "Se muitas coisas são postas junto umas das outras ou a seguir umas às

\footnotetext{
43 Id., Refl, AA 18: 343.

44 Baumgarten (1739) apud Kant (2007), AA 17: 44. A tradução do presente texto é devida ao Professor Doutor Leonel Ribeiro dos Santos, do Departamento de Filosofia da Faculdade de Letras da Universidade de Lisboa, a quem agradeço.

45 Kant (2007), Refl, AA 17: 44.

46 Cf., aqui, n. 43.
} 
outras." Assim, as coisas postas "junto umas das outras" competem à "harmonia"; as que se seguem "umas às outras", em contrapartida, à "melodia".

Uma nova passagem das "Preleções de Lógica" (Philippi) parece também movimentar-se no mesmo quadro referencial, no qual o primado recai sobre a "harmonia":

Na música, o melódico ou o tinido47 (Klang) dos sons é a matéria; mas a forma dos mesmos consiste na variação harmônica desses sons. No que concerne à matéria ou ao tinir, a um, então, pode ser agradável isto, a outro, o instrumento. Pois, nisso, ele depende da sensação, que é diferente nos diferentes sujeitos. Só que no atinente à forma da música, um concerto que é harmônico tem então de bem-soar a todos. ${ }^{48}$

\footnotetext{
47 Sobre a tradução de "Klang" e "Klingen" por "tinido" e "tinir" (opção que não será sempre a mais indicada), cf. Grimm (1854): "KLINGEN, klang, geklungen, sonare, tinnire [...]". No caso presente, lembrando-se que "tinir" indica um soar de forma aguda e vibrante, bem como que o "melódico", embora nem sempre de forma aguda, deve como tal sobressair, poder-se-á, desse modo, justificar a escolha de "tinido" para traduzir "Klang".

48 Cf. Kant (2007), V-Lo/Philippi, AA 24: 348-349. Cf. id., KU, AA 05: 212: "Einer liebt den Ton der Blasinstrumente, der Andre den von den Saiteninstrumenten." Sobre o vocábulo "Abwechselung", cf. id. ("WECHSELUNG, WECHSLUNG"). Em apoio de caráter histórico-filológico à compreensão que as expressões "in der harmonischen Abwechselung dieser Töne" e "ein Concert, was harmonisch ist" referem-se ambas à "harmonia" em seu significado matemático-musical, cf.: Zedler (1731) ("Verwechselung der Grössen (Permutatio quantitatum)". Registre-se, também, as expressões musicais, comuns na atualidade, "enharmonische Verwechslung / Verwechselung" e "enharmonische Modulation" (no jargão musical em língua portuguesa, preferencialmente: "modulação enarmônica"). Giordanetti, por sua vez, traduz "harmonische Abwechselung" por "alternanza armonica", e não, pois, como no jargão musical italiano: "variazione armonica". Sobre "Wohlklingen", cf. Sulzer (1771) ("Harmonie - (Musik)"): "Bisweilen drückt man das Wohlklingen, das gute Konsonieren oder das Zusammenfließen mehrerer Töne in einen, durch das Wort Harmonie aus. In diesem Sinne haben die Intervalle und Akkorde, die am meisten konsonieren, auch die meiste Harmonie und die vollkommenste Harmonie ist die, welche mehrere gleich hohe Töne oder die im Unisonus oder Einklang gestimmt sind, geben; weil sie so völlig in einander fließen, dass man keinen davon besonders unterscheidet." Já sobre "Wohlklang”, cf. Grimm (1854): "WOHLKLANG, m., angenehmer, schöner klang; wolklang dulcis harmonia [...]"; Meier (1752) apud Kant (2007), AA 16: 837 ("Wohlklang der Schreibeart (sonoritas stili)"). Com respeito a "Concert", por fim, a expressão tanto pode designar um conjunto de instrumentistas quanto uma forma musical; cf. SPITZER; ZASLAW (2011): “[...] In German the term Kapelle ("chapel') was widely employed in the 17th and 18th centuries as a name for court, church and private musical establishments, meaning instrumentalists and vocalists taken together. In addition Germans designated instrumental ensembles as Chor, die Musik, Konzert, Symphonie and die Instrumenten. The use of 'Orchester' in this sense turns up in German by 1713 as a borrowing from the French. [...]". Cf. Zedler (1731): "Concerto, Concert, I) ein Collegium Musicum, oder eine musicalische Zusammenkunfft. [...]"; Sulzer (1771): "Dieses Wort hat zweierlei Bedeutung. Es bezeichnet eine Versammlung von Tonkünstlern, die zusammen eine Musik aufführen; und bedeutet auch eine besondere Gattung des Tonstücks. [...]". Na presente passagem, "Concert" refere-se, creio, a conjunto instrumental.
} 
Tendo presente o que afirmava o filósofo, já em 1772, julgar a música ou crivála ao nível da razão exigirá o primado da matematicidade da "harmonia" sobre a sensorialidade da "melodia".

Em 1790, não será distinto o juízo de Kant a respeito:

[...] posto que aquelas ideias estéticas [“ideias estéticas naturalmente ligadas [à música]"] não são nenhuns conceitos nem pensamentos determinados, a forma de composição dessas sensações (harmonia e melodia) serve somente de forma de uma linguagem para [...] expressar a ideia estética de um todo consistente de uma indizível profusão-de-pensamentos, conforme a um certo tema, que constitui na peça o afeto dominante. Nessa forma matemática, embora não representada por meio de conceitos determinados, unicamente se apóia o comprazimento (Wohlgefallen) que a simples reflexão conecta [...] com esse jogo [das sensações] como condição de sua beleza, válida para qualquer um; e unicamente segundo ela o gosto pode arrogar-se um direito de pronunciar-se antecipadamente sobre o juízo de qualquer um. 49

Mas o que se lê na imediata sequência, embora não contrarie a logicidade do juízo-de-gosto musical, permite dar ao matemático a forma, ao sensorial a matéria; àquele a harmonia, a este a melodia:

[...] no estímulo e no movimento do ânimo que a música produz, a matemática certamente não tem a menor participação; ela é, sim, somente a condição indispensável (conditio sine qua non) daquela proporção das impressões, tanto em sua ligação quanto em sua variação [...].50

Será interessante examinar também o que Kant ressalta, no $§ 14$ dessa mesma terceira Crítica, o qual, intitulado "Elucidação por meio de exemplos", liga-se diretamente ao conteúdo do anterior, que trata do juízo-de-gosto puro:

Toda a forma dos objetos dos sentidos (do externo, como, mediatamente, também do interno) é ou figura ou jogo; no último caso, ou o jogo das figuras (a mímica e a dança, no espaço) ou o simples jogo das sensações (no tempo). O estímulo (Reiz) das cores ou o dos sons agradáveis do instrumento pode vir em acréscimo, mas o desenho no primeiro e a composição (Composition) no último constituem o objeto próprio do juízo-degosto puro. 51

\footnotetext{
49 Kant (2007), KU, AA 05: 328-329. Obviamente, na passagem "“...] die Form der Zusammensetzung dieser Empfindungen (Harmonie und Melodie)", "harmonia" e "melodia" não são as "sensações", mas a "forma" que as compõe (melhor, portanto, teria sido: as formas "da composição dessas sensações (harmonia e melodia)"). Sobre "[der] herrschende Affect", cf. id., V-Lo/Philippi, AA 24: 357-358 ("Hauptton", "tonalidade-dominante").

50 Id., KU, AA 05: 329.

51 Ibid., p. 226. Cf. ibid., p. 212 [texto já citado acima [cf. n. 47]]: "Einer liebt den Ton der Blasinstrumente, der andre den von den Saiteninstrumenten."
} 
A presença do "estímulo", em consequência, poderia representar não somente um aditivo, mas uma ingerência eventualmente maculadora, o que possibilitaria inferir, no limite, que a forma musical a consentir o juízo-de-gosto puro na música corresponderia a uma espécie de "Composition" não-sonorizada. Nesse caso, a talvez melhor maneira de escapar à intromissão sensorial comprometedora seria, em última instância, não executar a peça, mas tão-só inspecioná-la (sie nur einsehen). Beethoven surdo, portanto, seria, literalmente, o auditor perfeito, como "ouvinte"juiz, e Kant, por sua vez, deviria patrono avant la lettre da Musikwissenschaft!

Por fim, em 179252, considerando o "belo" nas "Preleções de Antropologia" (Dohna), Kant afirma:

[...] Tudo o que é belo agrada em pensamentos, no jogo; por exemplo, música. O homem que não pode refletir não encontra satisfação numa música consonante. [...] Os chineses amam somente a música de um único instrumento. Tão logo tem lugar o accompagnement, ela não lhes agrada mais. [...] Isso ocorre porque eles não refletem, não observam como os diferentes sons seguem-se uns aos outros e finalmente se consonam numa harmonia. $[\ldots]^{53}$

A despeito de muitos instrumentos poderem, por si próprios, emitir ao menos duas notas simultaneamente, formando, assim, determinados intervalos, "a música de um único instrumento" parece corresponder aí àquela música na qual o instrumento em questão reproduziria uma nota por vez. Tal resulta, como se sabe, no canto monofônico, ou naquele que, não tendo acompanhamento, é somente melódico. Kant parece, então, outra vez enaltecer o harmônico face ao melódico ("[...] sons [que] se seguem uns aos outros e finalmente se consonam numa harmonia"). Lê-se, ainda, em passagem das "Preleções de Lógica" (Philippi): "Um concerto54 é tanto mais agradável quanto mais instrumentos [nele] se consonarem" 55 .

\footnotetext{
52 Trata-se, com efeito da "39ste Stunde, Sonnabend, den 12. Januar 1792" (cf. Kowalewski (1924) apud Kant (2007), p. 201-202 [Ko201-202]).

53 Ibid., p. 202 apud Kant (2007). A frase imediatamente anterior à citada no início dessa passagem ("Tudo o que é belo agrada em pensamentos, no jogo; por exemplo, música. (Alles, was schön ist, gefällt in Gedanken, im Spiel, z.E. Musik.)"), afirma: "O intervalo entre as representações e os conceitos de um objeto é reflexão. (Das Intervallum zwischen den Vorstellungen und den Begriffen eines Gegenstandes ist Reflexion.)" (ibid., p. 201-202 apud Kant (2007)) De acordo com ela, pode-se conjeturar sobre o significado musical que aí tenha "Intervallum". Já sobre o emprego musical do plural "Intervalle", cf. Kant (2007), Refl, AA 14: 394; id., "Vorlesungen über Physik (Friedländer), AA 29: 85. Por outro lado, cf.: The History of China (1755), p. 222: "The Chinese seem to like our vocal music well enough, provided that it be performed by a single voice, and repeated in chorus at the end of the period ; but as to finging in different parts, and the contrast betwixt voices and instruments, this they treat not only as disharmony, but as ridiculous cacophony."

54 A propósito do significado de "Koncert" na presente passagem, cf., aqui, n. 48.

55 Kant (2007), V-Lo/Philippi, AA 24: 366.
} 


\section{Considerações finais}

Kant dirige-se à música não só em função do estético, mas também em virtude do potencial analógico que ela abriga. Consoante tal fato, tratou-se aqui de um contato preliminar com essa imbricação analógico-exemplificativa entre filosofia e música, somente, não se tendo levado em conta - para além do aspecto estético, tampouco examinado - as considerações do filósofo sobre a física do som, dada sua reduzida importância na economia do tema em pauta. A partir de fragmentos selecionados, em especial das "Reflexões" e das "Preleções", destacou-se o par "harmonia" - "melodia", observando-se, então, a proeminência do harmônico face ao melódico.

As analogias musicais em Kant têm uma função estratégico-argumentativa, a qual, porém, sobre em nada modificar a classificação estética reservada por ele à música, decorre, em verdade, da própria sensorialidade peculiar a essa arte, ou, como diz o filósofo, do fato de ela ser "[...] um belo jogo de sensações (ein schönes Spiel von Empfindungen)" 56 . Ora, "[t]odo som musical é similar (ähnlich) a certas expressões das paixões (gewisse Ausdrücken der Leidenschafften). A satisfação na música surge, talvez, da similitude (Aehnlichkeit ${ }^{57}$ ) que os sons musicais têm com as sensações recordadas com prazer" 58 . Nesse caso, a analogia musical, assentada em tal "similitude", pode ter explicada sua eficácia pelo fato que a coisa objeto de analogia se torna agora de algum modo sentida. Com isso, se, por exemplo, uma comparação embriológica é eminentemente conceitual, uma comparação musical, em contrapartida, é eminentemente sensorial.

Assim, quando Kant destaca:

Crusius explica os princípios reais da razão segundo o systema praeformationis [...]; Locke, como Aristóteles, segundo o influxus physicus; Platão e Malebranche, a partir do intuitus intellectualis; nós, segundo a epigênese, a partir do uso das leis naturais da razão $[\ldots]$

para dois dos autores nomeados (Crusius e o próprio Kant), faz-se uma analogia entre os domínios embriológico e especulativo com respeito à explicação (Erklärung) dos "princípios reais da razão", de forma que, por meio dela, a explicação dos princípios reais da razão por Crusius está para a explicação dos princípios reais da razão por Kant, como "systema praeformationis" está para "epigenesis".

56 Id., KU, AA 05: 324. Cf. id., Anth, AA 07: 155: "ein regelmäßiges Spiel von Empfindungen des Gehörs"; id., Refl, AA 15: 267: "Das Spiel der Eindrüke ist Music.”; ibid., p. 329 ("[das] harmonische Spiel der Empfindung"); ibid., p. 358 ("Das Spiel der Eindrüke"); ibid., p. 849 ("Das bloße Spiel der affecten $[\ldots]$ "..).

57 Cf. Grimm (1854): “ÄHNLICHKEIT, $f$. similitudo, analogia."

58 Kant (2007), V-Lo/Philippi, AA 24: 358. 
Com isso, por mais que a proporção estabelecida nessas linhas permita afastar de Kant a hipótese inatista (ao menos, a de um inatismo radical), não há aí nenhuma espécie de sensificação, seja da forma crusiana de explicação dos "princípios reais da razão", seja da kantiana. Nesse caso, tal exemplo de analogia embriológica não ultrapassa o nível especificamente conceitual, comum a todos os termos da proporção. Em contrapartida, a particularidade da analogia musical se caracteriza por uma transferência de nível, pelo que o conceitual é deslocado para o sensitivo. Todavia, a especificidade e a eficácia da analogia musical só são plenamente estabelecidas quando se tem presente a "similitude" entre os sons musicais e "certas expressões das paixões". Numa palavra: quando se tem presente a sensorialidade peculiar a essa arte, ou, como diz o filósofo, o fato de ela ser "um belo jogo de sensações".

A posição geral kantiana sobre a música terá, por um lado, um componente rameauniano-intelectualista, e, por outro, um componente rousseauniano-sensorialista. Do ponto de vista musical, o primeiro componente se identificará com a matematicidade da harmonia; o segundo, em contrapartida, com a sensorialidade da melodia. Embora não de modo absoluto, as considerações presentes nas referências teórico-musicais e estético-musicais de Kant parecem indicar uma inclinação pela harmonia, e, pois, pelo intelectualismo ou formalismo estético em música. Todavia, no âmbito do rico metaforismo kantiano, as analogias musicais do filósofo, em sua função estratégico-argumentativa, prestam tributo ao sensível, ainda que em favor do conceitual. Na verdade, são elas que mais intensamente prestam um tal tributo, o que, se testemunha a fartura sensória da música, exibe, no mesmo passo, uma privação correspondente por parte do intelecto, ainda que, por definição, ele não possa apresentar-se de outro modo. Mas esse intelecto, sempre ectípico, é dito ser "carente de imagens (der Bilder bedürftigen)" 59 , ou seja, carente de um "dado múltiplo ([das] mannigfaltige [...] Gegebene ${ }^{60}$ )" que lhe permita chegar ao objeto de conhecimento. A despeito de não se tratar agora do conhecer, mas da compreensão ou interpretação do processo de conhecimento, o intelecto ectípico carente de imagens é o mesmo que, encontrando amparo hermenêutico na sensorialidade da analogia musical, poderá também qualificar-se de carente de sons musicais. Se assim for, a música terá um papel de não somenos importância na exegese do pensamento crítico, competência que, parece, o próprio Kant foi quem primeiro reconheceu e estabeleceu.

59 Id., KU, AA 05: 408.

60 Id., KrV, B 143. 


\section{Referências}

ADICKES, E. (1911): Einleitung in die Abtheilung des Handschriftlichen Nachlasses (III. Art des Abdrucks, en Kant im Kontext III - Komplettausgabe - Werke, Briefwechsel, Nachlaß und Vorlesungen auf CD-ROM. Herausgegeben von Karsten Worm und Susanne Boeck. 1. Aufl., Berlin.

Bartel, D. (1997): Musica Poetica. Musical-Rhetorical Figures in German Baroque Music, Lincoln, University of Nebraska Press.

Baumgarten, A.G. (1739): Metaphysica, en KANT, Gesammelte Schriften, AA 17 Deutsches Wörterbuch von Jacob und Wilhelm Grimm. (1854): Disponível em: $<$ http://germazope.uni-trier.de/Projects/WBB/woerterbuecher/dwb/ wbgui?lemid=GA00001>. Acesso em: 02 jun. 2011.

FERrARI, J. (1985): La querelle Rousseau-Rameau. Disponível em : $<$ www.rodoni.ch/OPERNHAUS/indesgalantes/querellerousseaurameau.PDF>. Acesso em: 02 jun. 2011.

GiordanetTi, P. (2001): Kant e la musica, Milano, CUEM.

HirschmanN, W. (1999): Zwischen Wissenstransfer und kritischer Lektüre, en Schneider, H. (Hrsg.) Studien zu den deutsch-französischen Musikbeziehungen im 18. und 19. Jahrhundert, Hildesheim, Georg Olms.

The History of China: Upon the plan of Mr. Rollin's Antient history. (1755): London, J. and P. Knapton.

Kant, I. (2007): Kant im Kontext III - Komplettausgabe - Werke, Briefwechsel, Nachlaß und Vorlesungen auf CD-ROM. Herausgegeben von Karsten Worm und Susanne Boeck. 1. Aufl., Berlin.

Kowalewski, A. (Hrsg.) (1924): Die philosophischen Hauptvorlesungen Immanuel Kants. (1924): Nach den neu aufgefundenen Kollegheften des Grafen Heinrich zu Dohna-Wundlacken. Rösl \& Cie., München und Leipzig, en Kant, I. (2007): Kant im Kontext III - Komplettausgabe - Werke, Briefwechsel, Nachlaß und Vorlesungen auf CD-ROM. Herausgegeben von Karsten Worm und Susanne Boeck. 1. Aufl., Berlin..

MARPURG, F.W. (1757): Systematische Einleitung in die musicalische Setzkunst nach den Lehrsätzen des Herrn Rameau. Aus dem Französischen übersetzt und mit Anmerkungen vermehret v. F. W. Marpurg, Leipzig.

MeIER, G.F. (1752): Auszug aus der Vernunftlehre, en Kant im Kontext III Komplettausgabe - Werke, Briefwechsel, Nachlaß und Vorlesungen auf CDROM. Herausgegeben von Karsten Worm und Susanne Boeck. 1. Aufl., Berlin. RAMEAU, J.-P. (1754): Observations sur notre instinct pour la musique, et sur son principe. Disponível em: <http://www.chmtl.indiana.edu/tfm/18th/ RAMOBS TEXT.html>. Acesso em: 02 jun. 2011

Rousseau, J.-J. (1824): Essai sur l'origine des langues, Paris, Dupont. 
SERWER, H. "Marpurg, Friedrich Wilhelm". (2011): Oxford Music Online. Disponível em: <http://www.oxfordmusiconline.com/subscriber/article/grove/ music/50046>. Acesso em: 02 jun. 2011.

Spitzer, J.; ZASLAW, N. (2011): Oxford Music Online. Disponível em: $<$ http://www.oxfordmusiconline.com/subscriber/article/grove/music/20402>. Acesso em: 02 jun. 2011.

Sulzer, J.G. (1771): Allgemeine Theorie der Schönen Künste. Disponível em: $<$ http://www.textlog.de/sulzer_kuenste.html $>$. Acesso em: 02 jun. 2011.

ZEDLER, J.H. (1731): Grosses vollständiges Universallexicon aller Wissenschaften und Künste. Disponível em: <http://www.zedler-lexikon.de/>. Acesso em: 01 mai. 2011.

Ubirajara Rancan de Azevedo Marques

Departamento de Filosofia

Faculdade de Filosofia e Ciências

Universidade Estadual Paulista "Júlio de Mesquita Filho" ubirajara.rancan@gmail.com 